\title{
Entre a organização do trabalho e o sofrimento: o papel de mediação da atividade
}

\author{
JÚLIA IsSY ABRAHÃo \\ Universidade de Brasília \\ E-mail: abrahao@unb.br \\ Camila Costa Torres \\ Universidade de Brasília \\ E-mail: torres@unb.br
}

\begin{abstract}
Resumo
Os modelos de organização do trabalho, em geral, não contemplam a flexibilidade necessária para lidar com as situações variadas e complexas. Os trabalhadores, nesse contexto, desenvolvem estratégias, que muitas vezes burlam as normas, mas propiciam melhores resultados na execução da atividade e na economia psíquica dos sujeitos. Este estudo pretende ilustrar como elementos da organização do trabalho contribuem ou dificultam a execução de tarefas nas quais o trabalhador é confrontado a situações críticas, sendo solicitado durante a jornada a responder demandas, solucionar problemas e tomar decisões sob pressão temporal. 0 artigo é desenvolvido tendo como suporte empírico um estudo de caso realizado numa central de atendimento.
\end{abstract}

Palavras-chave

Ergonomia, psicodinâmica do trabalho, organização do trabalho, central de atendimento.

\section{Between work organization and suffering: the mediation role of the activity}

\begin{abstract}
Models of work organization do not usually consider the necessary flexibility in dealing with complex and varied job situations. Within this context, strategies that sometimes cheat rules or norms are developed by employees. These strategies may produce better task results and cognitive economy for them. This study aims to discuss how work organization elements may either to make difficult or help employees under critical working conditions. That is, situations in which workers are required to respond to demands, take decisions and problem solving under time pressure. This paper is supported by empirics data from the results of the study realized in the call-center.
\end{abstract}

\section{Key words}

Ergonomics, work psychodinamics, work organization, call-center. 


\section{INTRODUĈ̣̃O}

No processo de evolução do trabalho mudaram-se os conceitos, os parâmetros, as metas, os objetivos, as formas de ver e de fazer. $\mathrm{O}$ trabalho foi se moldando às novas configurações da realidade e da sociedade, se adaptando às tarefas e às suas exigências. $\mathrm{O}$ trabalhador deixou de ser o executor e passou a assumir o controle das máquinas, planejadas para minimizar o custo do trabalho e maximizar a produtividade.

Nesse contexto, as mudanças são mais profundas e nem sempre podem ser observadas diretamente; não são apenas desenvolvidas novas tarefas ou novas funções, são novas competências, outras formas de executar e de organizar o trabalho que se configuram. Esses ambientes primam por atividades que requerem habilidades de processamento rápido e eficaz das informações, capacidade de antecipar momentos críticos e solucionar problemas.

Nas situações em que a natureza da atividade implica resolução de problemas e tomada de decisões, a organização do trabalho, responsável pelas regulamentações, assume um papel determinante. Ela pode contribuir para a melhoria dos espaços de resolução de problema ou, ao contrário, restringir as possibilidades definindo regras que inviabilizam a manifestação dos saberes acumulados ou da criatividade resultante da articulação de outras competências.

A organização do trabalho influencia o planejamento, a execução e a avaliação, permeando todas as etapas do processo produtivo. Ela prescreve normas e parâmetros que determinam quem vai fazer, o que vai ser feito, como, quando e com que equipamentos/instrumentos; em que tempo, com que prazos, em que quantidade, com que qualidade, enfim, a organização do trabalho constitui a "viga central" da produção.

Considerando as tantas transformações ocorridas é normal também esperar que a organização do trabalho tenha se transformado. Afinal, desde a Organização Científica do Trabalho - OCT, de Taylor, muitas outras escolas despontaram. No entanto, quase todas elas guardam, nos seus princípios, resquícios da OCT. O que se questiona hoje é se os modelos vigentes são compatíveis com as exigências das novas configurações do mundo do trabalho.

O novo taylorismo é o modelo de organização do trabalho adotado nas centrais de atendimento, a cadência é determinada por ritmos elevados e pelo controle permanente das ações. O sistema de controle é contraditório em tarefas que solicitam cooperação nas interações de trabalho com possíveis reflexos na saúde dos trabalhadores. A presença de padrões rigorosos de execução e de pressão temporal restringe as complexas inter-relações que se estabelecem na atividade para cumprir sua função. Dores e tensões podem refletir uma sobrecarga proveniente das confronta- ções entre as distintas lógicas atuantes na situação de trabalho, que demandam estratégias de regulação frente às normatizações, regras impostas e cobranças rígidas (ABRAHÃO e SANTOS, 2004).

Contudo, esta modalidade de gestão é incongruente com a natureza do trabalho de teleatendimento, marcado pela complexidade das tarefas, pela necessidade de cooperação atendente-cliente e pelas ações mediadas por artefatos tecnológicos (TORRES, 2001; GUBERT, 2001; SANTOS, 2002).

Assim pode-se dizer que nas centrais de atendimento ainda vigoram os princípios tayloristas, principalmente, o controle rigoroso, a divisão de tarefas e a pressão temporal para produção, sendo uma das consequiências deste modelo de gestão, amplamente utilizado nas centrais de atendimento, os danos à saúde dos trabalhadores, que apresentam queixas de sobrecarga, que se manifestam sob a forma de dores, tensões, lesões e até síncopes nervosas (ABRAHÃO e SANTOS, 2004).

Este artigo pretende ilustrar como elementos da organização do trabalho, em uma central de atendimento, contribuem ou dificultam a execução de tarefas nas quais o trabalhador é confrontado a situações críticas, sendo solicitado a responder às demandas, solucionar problemas e tomar decisões sob pressão temporal. Os resultados apresentados ao longo deste artigo têm sua origem em um estudo de caso, realizado por Torres (2001), em uma central de atendimento em que a natureza do trabalho e o modelo de gestão, sobretudo a questão do controle exercido exemplificam a problemática levantada. Os dados foram reorganizados e recortados com o intuito de ilustrar outra face da problemática estudada pela autora.

Adotam-se, como suporte teórico, os pressupostos da Ergonomia articulados aos construtos da Psicodinâmica do Trabalho. Nesse percurso, busca-se examinar a natureza do trabalho e as formas de controle da organização, bem como seus efeitos sobre os operadores, a partir da diferenciação entre o prescrito e a atividade, evidenciando: a natureza do controle da organização sobre os operadores; as estratégias por eles elaboradas como forma de minimizar as exigências afetivas e cognitivas da atividade; a rotatividade e o absenteísmo como manifestações de mal-estar no trabalho.

É importante salientar que trabalhar na perspectiva da dinâmica psíquica ou da dinâmica da atividade implica em pressupostos diferentes. No entanto, o que se pretende ao propor uma articulação é apontar a complementaridade entre as abordagens.

Wisner (1990), ao cotejar as duas disciplinas, apontou para esta possibilidade ao identificar os limites da análise ergonômica - AET. Ele cita como exemplo a dificuldade da AET em mostrar a ansiedade que emerge nas situações críticas. E ainda, de explicar como os operadores fazem 
para manter seu comportamento e atitudes habituais e responder satisfatoriamente ao modelo de excelência vigente. Nesse sentido, a Psicodinâmica agrega conhecimentos à Ergonomia e sua contribuição se dá, sobretudo, na compreensão da repercussão do trabalho na vida psíquica do sujeito e na forma como ele administra esta vivência.

Onde encontrar explicação para tais fenômenos e indagar sobre o sustentáculo da normalidade? Quais as conseqüências da sua manutenção? E, por fim, como se materializa a ruptura da mesma na perspectiva do sujeito e da organização?

O pressuposto aqui defendido é que uma das formas de se construir a resposta para essas questões, possivelmente, se encontra na articulação da ergonomia com a psicodinâmica do trabalho, malgrado as especificidades pleiteadas, a justo título, por ambas as disciplinas. Busca-se de certa forma, identificar como o sujeito articula suas diferentes competências, tanto na dimensão psíquica quanto na cognitiva, frente à imprevisibilidade da realidade, considerando a articulação da variabilidade inter e intra-individual e a decorrente do contexto de trabalho (ABRAHÃO, 2000).

\section{A Ergonomia e sua contribuição}

$\mathrm{O}$ fato de a automação e a informatização no mundo do trabalho trazer consigo tarefas cujas exigências são de natureza predominantemente cognitiva solicita da ergonomia o desenvolvimento de novas abordagens teórico-metodológicas para apreender o funcionamento do homem de forma situada (RASMUSSEM, 2000; MARMARAS \& KONTOGIANS, 2001; MARMARAS \& PAVARD, 1999).

O trabalho constitui para a ergonomia seu objeto central de análise. Ele é compreendido como uma atividade finalística, ou seja, destinada a atingir um objetivo, de caráter individual ou coletivo, organizado segundo prescrições, por vezes lacunar e realizada em um contexto particular (TEIGER, 1992; DEJOURS \& MOLINER, 1994; TERSSAC, 1995). O trabalho revela características especificamente humanas, como a capacidade de criação e produção de bens específicos, bem como permite a inserção do sujeito em um contexto social, em função de uma atividade a ser executada.

A compreensão da cognição nas situações laborais para a ergonomia implica em apreender a forma pela qual os processos cognitivos são solicitados e como eles se manifestam na ação de trabalho. Nesse processo, ela se apóia em conceitos da psicologia cognitiva, às vezes reformulando-os e, quando possível, conferindo-lhes aplicabilidade a partir de dados empíricos.

Nesse sentido, por exemplo, o conceito de representação assume um sentido para a Ergonomia quando associado a uma ação. Essas representações, segundo WeillFassina e Cols. (1993), podem ser caracterizadas como produto e como processo. No primeiro caso, refere-se às redes de propriedades, de conceitos, de saberes, de habilidades, de crenças e de experiências construídas no decorrer da história do indivíduo, a partir da sua relação com o trabalho. Como processo, as representações para a ação tratam da elaboração individual e finalística pela qual são construídos e estruturados os conteúdos do sujeito frente ao contexto de trabalho. utilizadas e desenvolvidas pelos sujeitos, em função das exigências do processo de trabalho, a ergonomia busca apreender uma parte da realidade do trabalho que se manifesta nos sujeitos e é estruturada individualmente ou pelo coletivo de trabalhadores.

A compreensão do componente cognitivo do trabalho se apóia na relação entre os conhecimentos constituídos e armazenados pelos sujeitos e os traços de memória referentes à situação, formulados ou reformulados para a ação e pela a ação. É esta relação que subsidia a noção de representações para a ação (WEILL-FASSINA e COLS, 1993).

Na memória de trabalho são articuladas as construções dos significados das situações que levam à ação, por meio de discriminações perceptivas, buscas de associação causal, avaliações, controles de conduta, antecipação de novas propriedades da situação, construção de estratégias e táticas, conduzindo a esquemas de ação (CANÃS \& WAERNS, 2001).

No entanto, em diferentes situações, os operadores nem sempre dispõem, no momento desejado e na forma adequada, de informações claras e pertinentes necessárias para a tomada de decisão mais apropriada. Situação esta agravada quando eles não dispõem dos meios necessários para acompanhar de forma permanente as decisões políticas e as novas regras que delas decorrem.

Todo esse processo acaba por gerar nos trabalhadores angústia, ansiedade, toda uma gama de sentimentos, para os quais a ergonomia não possui ferramentas que permitam explicá-los. Esta lacuna é justamente o espaço de articulação entre a ergonomia e a psicodinâmica do trabalho. 


\section{A Psicodinâmica do Trabalho}

A Psicodinâmica do Trabalho dedica-se à análise dinâmica dos processos psíquicos envolvidos na confrontação do sujeito com a realidade de trabalho. O seu interesse é voltado para as vivências subjetivas dos sujeitos, a intersubjetividade que permeia o trabalho e o lugar ocupado pelo trabalho nos processos de regulação psíquica (DEJOURS, ABDOUCHELI \& JAYET, 1994).

$\mathrm{O}$ trabalho constitui um elemento fundamental da existência humana, podendo contribuir para o bem-estar ou, para a manifestação de sintomas que afetam a saúde. A organização do trabalho é considerada como mediadora desse processo. Ela é compreendida como a divisão do trabalho, incluindo a divisão das tarefas, a repartição, a definição das cadências, o modo operatório prescrito; e a divisão de homens, repartição de responsabilidades, hierarquia, comando, controle.

te do desejo do sujeito. Desse confronto, emergem as estratégias defensivas responsáveis, em parte, pela manutenção do equilíbrio do sujeito ou do coletivo de trabalhadores.

\section{0 método}

Este estudo adotou os procedimentos propostos pela Análise Ergonômica do Trabalho - AET, seguindo o modelo de intervenção de Guérin e Cols (1991). Os dados de natureza quantitativa, os referentes à organização estudada e as verbalizações foram obtidos via análise da atividade, por meio de observações sistemáticas, consultas à documentação da empresa e entrevistas. As falas dos operadores que ilustram o artigo foram extraídas das reuniões coletivas, realizadas junto com as operadoras da central, nos moldes propostos pela abordagem da Psicodinâmica do Trabalho (DEJOURS, ABDOUCHELI \& JAYET, 1994).

A demanda inicial teve sua origem em um projeto de consultoria, que sofreu desdobramentos, resultando em uma demanda específica para a central de atendimento, por parte da direção e dos atendentes. Ao proceder o recorte do objeto de estudo buscou-se entre os

Quando o trabalho é escolhido e organizado livremente, a vivência do conflito é minimizada, e torna-se um espaço para a descarga psíquica e alívio da tensão. Entretanto, quando esse processo é cerceado propicia um acúmulo de tensão, que pode ter repercussões sobre o corpo, são as chamadas reações somáticas (DEJOURS, ABDOUCHELI \& JAYET, 1994).

As vivências de prazer são identificadas a partir de manifestações de realização, satisfação ou gratificação das pulsões, remetendo ao conceito de sublimação da psicanálise (KUPFER, 2000; RAPPAPORT e COLS, 1981), definido como a derivação de uma pulsão para um alvo nãosexual, tornando possível que o indivíduo se volte para atividades como a produção científica ou artística e todas aquelas que visam um aumento do bem-estar e da qualidade de vida. Em contrapartida, as vivências de sofrimento resultam dos conflitos, não resolvidos, decorrentes da relação estabelecida com os preceitos da organização do trabalho.

Pode-se afirmar que para a Psicodinâmica, o trabalho em si não constitui o objeto de análise. Mesmo tendo sido livremente escolhido pelo sujeito e tendo afinidade com seu desejo, ele não é livremente organizado, estando o sujeito limitado e impossibilitado de obter integralmente a satisfação do seu desejo.

Assim, ao trabalhador cabe agir sobre o imprevisto, o inesperado. Logo, nesta condição, o trabalho constitui a gestão de imprevistos, que provavelmente, configurar-se-ão como problemas a serem resolvidos. Realidade muito distan- resultados aqueles que permitiam explicitar as questões levantadas na introdução deste artigo. Eles visam ilustrar elementos da organização do trabalho que podem contribuir ou dificultar a execução de tarefas em um contexto no qual o trabalhador é confrontado a situações críticas, solicitado a responder às demandas, solucionar problemas e tomar decisões sob pressão temporal. Parafraseando Vilela e Assunção (2004), a análise do trabalho permite apreender as regras da organização, pela via da objetivação dos dados que as fundamentam.

A pesquisa foi realizada na central de atendimento de um departamento de trânsito, sendo sua função principal prestar informações sobre a situação dos veículos e orientar a população a respeito dos procedimentos usuais da organização. Os serviços de atendimento são prestados por uma empresa terceirizada e controlados por uma estatal.

A central de atendimento, à época do estudo, contava com um efetivo de 50 atendentes, a maioria do sexo feminino $(68 \%)$, e quatro supervisores, sendo três do sexo masculino e um do feminino. A faixa etária situava-se no intervalo compreendido entre 18 e 35 anos.

\section{Natureza das tarefas e o conteúdo da atividade na central de atendimento}

Os resultados da análise do trabalho identificaram as exigências e a natureza das solicitações implícitas na atividade dos operadores, entre elas: 
1. memória: para armazenar dados, códigos, senhas, informações mais freqüentes, modo de funcionamento do sistema, regras, normas;

2. capacidade de detectar, discriminar e interpretar o conteúdo das demandas dos usuários, com o intuito de transmitir-lhes uma resposta satisfatória.

A análise da atividade destes operadores mostra que na operacionalização da tarefa, aparentemente de natureza cognitiva, ela é de fato permeada por atividades que impactam no aparelho psíquico. Os resultados de 26 horas de observação sistemática apontam que 19\% dos atendimentos (Atendimentos críticos) fugiam ao prescrito pela organização, exigindo a adoção de estratégias operatórias na tentativa de resolver as demandas dos usuários. A apresentação de um destes atendimentos revela as tentativas do operador de suprir lacunas no desempenho do trabalho que são essenciais para a concretização do mesmo.

“............ bom dia.

Eu queria saber de um veículo?

Qual é a placa

JEK 6368, ano 82, modelo 83.

Operador Digita a placa, recebe informação do sistema - argumento não encontrado.

Sr. esta placa é de.........?
............. JEK6368.
Argumento não encontrado, veículo não cadastrado.
Não tá cadastrado não, é? Quando tá assim é o quê?
Ou o veículo não é de .............. ou tem alguma letra ou
número errado
É de ........, deixa eu confirmar... é JEK 6368.

Operador digita novamente a placa e recebe novamente a mensagem do sistema - argumento não encontrado

Não consta. Sr. vou tentar em outros estados, só um momento.

Tá bom.

Muda de tela, sai da tela de placas local e entra na tela de consulta nacional, digita a placa, recebe informação do sistema - argumento não encontrado.

Veículo não cadastrado, realmente algum número ou letra está incorreto, o sr. verifica a placa e retorna a ligação, está bem?!.

Pôxa, tá beleza, então.

Nosso atendimento é de 07:00 às 21:00, a partir das 18:00 fica mais fácil.
Tá, tá beleza, então.

Bom dia, a (empresa) agradece a sua ligação."

As frases do operador refletem os momentos em que ele identifica falhas na demanda e recorre a sua experiência para constituir corretamente o problema. A estratégia operatória adotada é a de antecipação, pois o operador evoca na memória outras situações já vivenciadas para, então, indagar ao usuário sobre a pertinência dessas novas possibilidades. Ao investigar juntamente com o usuário o erro contido na demanda, ele busca possíveis soluções que permitam identificar o problema, criando um outro espaço de resolução do problema. Assim procedendo, a estratégia operatória elaborada constitui, também, um mecanismo de regulação que contribui para a manutenção de seu equilíbrio psíquico.

Na primeira frase, o operador detecta a falha na demanda a partir da resposta do sistema. Ao processar a resposta do sistema, ele aciona um outro repertório constituído por seu savoir-faire e suas representações para a ação. Neste momento ele reinterpreta o problema e se antecipa, questionando a localidade da placa para encontrar uma solução, ao invés de informar ao usuário que o argumento não havia sido encontrado. Tal estratégia permite conduzir o diálogo com o usuário e obter as informações necessárias, ao mesmo tempo, evita expor sua dificuldade em obter o dado desejado. Assim fazendo, ele adia as possíveis manifestações negativas por parte do interlocutor.

$\mathrm{Na}$ segunda frase, o operador reconstrói o problema apoiado nas suas representações para a ação que incorporam novas informações sobre o contexto. Ele tenta sanar o problema, buscando compreender a natureza do erro, verificando os dados fornecidos pelo usuário. A estratégia falha, pois o usuário confirma a placa e ela continua como argumento não encontrado, ou seja, o operador busca identificar a falha na demanda juntamente com o usuário e não consegue. O que elimina uma das possíveis causas do erro.

A terceira frase revela uma nova tentativa do operador em diagnosticar e interpretar o problema. Ele verifica se a placa não é de outro estado, situação de retrabalho, pois no início do diálogo ele já havia questionado a localidade da placa e o usuário manteve a informação, esta estratégia também falha e o resultado é um atendimento inconcluso e possivelmente frustrante.

A verbalização abaixo ilustra como ocorre a interação entre o operador e o usuário e confirma a problemática levantada em torno da imprecisão da demanda.

"A maior dificuldade é lidar com o usuário, porque a gente pega todo tipo de gente, muito educada e aqueles que descontam tudo na gente. Tem que saber separar porque quando chego em casa, às vezes, ainda estou estressada." 
Este não é um exemplo pontual, pois situações idênticas ou similares foram encontradas em 13 das 14 observações sistemáticas realizadas sem escuta e nas 12 observações sistemáticas realizadas com escuta (60 min. cada).

Tal resultado revela que os operadores não se dão conta de que uma parte da sua carga de trabalho, que não é residual, resulta justamente da operacionalização das prescrições subjacentes às normas e regras determinadas pela organização do trabalho. É neste espaço de diferença que emergem as situações críticas e problemáticas, nas quais eles utilizam recursos de natureza cognitiva, psíquica e física e investem na tentativa de atingir os objetivos do trabalho, tentando minimizar a frustração e o sofrimento de se sentirem incompetentes ou mesmo cerceados pelas normas, na execução de sua atividade.
Convém ressaltar que esta situação pode ser agravada quando o suporte técnico-organizacional disponibilizado dificulta a atividade ao invés de apoiá-la. O sistema computacional, os subsídios instrumentais e o treinamento seriam outros exemplos que quando analisada sua pertinência revelam também a distância entre as prescrições e a atividade.

Este tipo de atendimento, portanto, comum nesta central, pode ser considerado como um fator que aumenta a carga de trabalho, pois exige dos operadores maior habilidade na comunicação, manutenção da paciência e da cordialidade em situações críticas, bem como a elaboração de estratégias para evitar o fracasso e a frustração resultante de um atendimento inconcluso. A resolução de problemas permeia de forma significativa a atividade dos operadores, no entanto, o espaço de resolução é restringido pelo script, acrescido do fato de saber que está transgredindo as normas - a prescrição não permite alteração dos procedimentos. Hipotetiza-se que a transgressão configura uma maneira de dar sentido ao trabalho.
A análise ergonômica mostrou com clareza as diferenças entre as prescrições e a atividade. Muitas vezes, os operadores deparam-se com demandas mal formuladas, incompletas ou incorretas, levando-os a reformulá-la, juntamente com o usuário, na expectativa de obter êxito no atendimento. Um atendimento com estas características foge completamente ao estipulado pela prescrição, que prevê que o operador apenas transmitirá a informação solicitada e que a mesma se encontra facilmente disponível no sistema.

\section{"O usuário que não sabe o que quer dificulta o nosso serviço, temos que ficar questionando, tentando adi- vinhar o que ele quer, esperando ele pegar o número da placa, a caneta para anotar...”}

A configuração da demanda do usuário influencia a qualidade do atendimento e, geralmente, também é um componente que aumenta o grau de complexidade da atividade. Ao expressar a sua demanda o usuário ativa uma série de processos cognitivos do operador. É a partir da sua demanda que ele desencadeia as seqüências de ações e funções mentais que resultarão na realização da atividade.

\footnotetext{
"Às vezes a gente erra por conta do jeito que vem a pergunta."

"Às vezes o usuário é muito leigo e aí a gente tem que passar para ele até ele entender, afinal de contas o nosso serviço é passar informações, tem gente que fica até 10 min."
}

\section{Natureza do controle do trabalho}

A empresa não determina uma quantidade específica de ligações a ser atendida, no entanto, ela é remunerada por chamadas atendidas. Evidentemente, sua meta é quanto maior a quantidade de atendimentos melhor seu rendimento, principalmente considerando a grande quantidade de demanda da população estimada em 600.000 potenciais usuários do serviço.

Com o intuito de assegurar a produtividade e a qualidade dos atendimentos, o controle é exercido por duas instâncias que coabitam na central de atendimentos: a prestadora de serviços e a empresa estatal.

A empresa prestadora do serviço é responsável pelo controle da qualidade do serviço de telemarketing (utilização correta da fraseologia, amabilidade com os usuários, objetividade) e pela qualidade dessas informações; executa também a observação dos atendentes na central, o recebimento e o encaminhamento dos formulários de pesquisa de informações à funcionária responsável da estatal e a avaliação dos operadores em dois quesitos:

1. acompanhamento pessoal, que inclui integração com a empresa, apresentação pessoal, interesse, liderança, higiene, organização do ambiente de trabalho, assiduidade, pontualidade;

2. desenvolvimento do operador, que considera presteza no atendimento, cordialidade com as pessoas, domínio do conteúdo, dicção e vocabulário, clareza e organização nas informações, habilidade de lidar com objeções, vícios de linguagem e finalização do atendimento. 
A empresa estatal é responsável pelo controle da qualidade do conteúdo das informações transmitidas, checando a sua fidedignidade junto à fonte.

As duas empresas exercem o controle por meio da monitoração informatizada dos operadores, durante os atendimentos. O sistema informatizado permite monitorar: 1) o status dos atendentes (atendente em pré-ligação, em espera, em operação e em pós-ligação); 2) o status das linhas (linhas usadas, linhas em URA, linhas em operação); 3) o status dos operadores (em operação, em suspensão, em espera, préligação, pós-ligação e logados).

Desta forma é instaurado na empresa um exacerbado sistema de controle, convergindo com os resultados apontados por Wisner (1987), Dejours (1987), Abrahão e Santos (2004) quando afirmam que o serviço de prestação de informações via telefone tem, geralmente, suas bases estruturadas em uma organização do trabalho rígida, influenciada pelos padrões tayloristas, na qual os horários, o ritmo e as pausas são determinados e controlados e as regras não são flexíveis ou adaptáveis.

A impossibilidade de transformar ou adaptar as determinações da organização do trabalho tais como o controle excessivo, o ritmo imposto pela fila de espera virtual constitui fonte de insatisfação ou de sofrimento a partir do momento em que os trabalhadores sentem esgotados seus recursos para transformação. Dejours (1985) aponta como um dos principais pontos de conflito e, por conseqüência, provocadores de sofrimento psíquico, as relações, muitas vezes rígidas, entre o trabalhador e a organização. Esta relação pode ser considerada como conflituosa por ter, de um lado, a expectativa do trabalhador e, do outro, a rigidez sobre o modo de funcionamento e produção da organização, impedindo o trabalhador de atribuir um sentido particular ao seu trabalho.

O uso do constrangimento, da intimidação e do medo como ferramentas gerenciais, obriga os trabalhadores a investirem suas inteligências na busca permanente de um estado de equilíbrio entre a realização das atividades e a impossibilidade de elaboração do sofrimento psíquico (KARAM, 2003).

As falas dos operadores ilustram o sentimento de chateação e irritação diante das cobranças e do controle ostensivo. Contudo, justificam a necessidade do mesmo para o funcionamento do serviço, desde que permita um espaço de autonomia, no qual seria possível a manifestação da criatividade, em face da variabilidade de situaçõesproblemas a que são confrontados. As falas abaixo refletem esta situação:

\footnotetext{
"Sabe, eu acho que o trabalho aqui seria bem melhor se não fosse tão rígido. Toda hora, tudo é motivo para controle. Até o tempo de ir ao banheiro é contado."
}

\begin{abstract}
"Fico mal com o controle, se não for como eles (gerentes) mandam leva advertência ou é demitido..."

"Uma das coisas que é ruim aqui é a padronização, porque você tem usuário de todo tipo e às vezes eles não entendem o que a gente diz, se é padronizado é ruim. Eu queria ter mais liberdade para explicar."
\end{abstract}

O trabalho se torna ameaçador para o aparelho psíquico, na medida em que se opõe à sua livre atividade. " $/ . . . / \mathrm{em}$ termos econômicos, o prazer do trabalhador resulta da descarga de energia psíquica que a tarefa autoriza, o que corresponde a diminuição da carga psíquica do trabalho" (DEJOURS, ABDOUCHELI \& JAYET, 1994).

"A pressão aqui é muito grande, não pode isso, não pode aquilo."

Assim, o sofrimento emerge e nem a atividade, nem a relação hierárquica permitem a descarga de energia psíquica. Na impossibilidade de se desvincular do trabalho, os atendentes reinterpretam a situação, justificando para poder aceitá-la (TAJFEL, 1982). Neste caso específico, a estratégia adotada é atribuir a origem do sofrimento à relação que estabelecem com seus supervisores, ex-colegas de trabalho, ao invés de se reportarem diretamente à própria natureza do trabalho e aos constrangimentos dela decorrentes. Eles transferem aos supervisores a insatisfação conseqüente do sistema de controle, abstraindo o fato de que os supervisores também estão submetidos às normas e prescrições da função.

"Eu mudaria os supervisores, assim, a forma de tratamento dos supervisores."

"Se fosse possível eu mudava a supervisão; os supervisores são distantes dos operadores, parece que se esqueceram de quando eram operadores."

"Ah, eu colocaria supervisores mais qualificados, mais humanos."

Atenuar o sofrimento, como afirma Dejours (2003), passa freqüentemente por uma tentativa de negação da percepção de sua causa. Por esta razão, os trabalhadores nunca falam diretamente de suas defesas e tentam dissimulá-las para poderem resguardar suas identidades e mantê-las positivadas.

\section{As estratégias operatórias e o processo de regulação}

Dentre as estratégias operatórias identificadas, a anteci- 
pação do conteúdo da demanda dos usuários e a substituição do alfabeto fonético internacional por palavras mais próximas do cotidiano dos usuários são exemplos que refletem as dificuldades de funcionamento segundo as prescrições.

A antecipação foi observada, sobretudo diante da imprecisão dos usuários em relação às suas demandas. Os operadores evocam em sua memória possibilidades que permitam agilizar a comunicação com o usuário. O diálogo abaixo ilustra uma dessas situações:

"Eu quero saber como está o meu carro".

"O senhor deseja saber sobre multas, licenciamento, IPVA......"

"Isso, eu quero saber se tenho multas"

O operador, ao resignificar a demanda, é compelido a modificar seu modo operatório, independente dos constrangimentos e das suas conseqüências, como, por exemplo, burlar as especificações da organização do trabalho, com o intuito de atingir os objetivos determinados. Ao realizar tais operações ele está, também, recorrendo às suas competências, a ponto de se tornar capaz de "prever" as possibilidades de atendimento que respondam a demanda do usuário.

cultavam a compreensão dos usuários ao invés de facilitar a comunicação.

Considerando que a clientela abrange diferentes segmentos da sociedade e atende pessoas com níveis variados de escolaridade e formação, os operadores adotam vocábulos familiares aos usuários. Este procedimento acabou sendo generalizado para todas as letras do alfabeto.

Tanto a antecipação quanto a substituição do alfabeto fonético internacional são estratégias fundamentais para minimizar o custo da inadequação da prescrição no desempenho da atividade.

A primeira estratégia citada é considerada pela hierarquia como um processo criativo que demonstra iniciativa, pois sua ação agiliza o atendimento. Enquanto que a segunda, passa por caminhos que se distanciam das prescrições e constitui uma transgressão. Como, em geral, essas prescrições têm um caráter normativo, "bem trabalhar implica sempre, de uma maneira ou de outra, cometer infrações" (DEJOURS, 2003). O que é paradoxal nesta situação é o julgamento da hierarquia que não confere valor semelhante a ambas as estratégias, malgrado o fato de que os operadores ao recorrem a elas dêem inteligibilidade à comunicação.

A elaboração dessas estratégias revela lacunas na organização do trabalho, que ao prescrever, não considera as características dos usuários do serviço, portanto as normas se mostram incapazes de contemplar a variabilidade das situações reais, com as quais os operadores são confrontados cotidianamente.

Além de interagirem, os diferentes fatores que se articulam na composição da atividade variam ao longo do tempo, propiciando uma constante atualização desta interação. Segundo Guérin e Cols (1991),

No início do processo de consulta, os operadores devem indagar ao usuário a placa do veículo, em seguida soletrar as letras associando-as a vocábulos predeterminados e só após a confirmação eles iniciam o procedimento de inserção de dados no sistema. Caso ela seja, por exemplo, JFB 0550 o operador, seguindo as determinações, deveria confirmar os dados da seguinte forma: $\mathbf{J}$ deJuliete, $\mathbf{F}$ de Fox e B de Bravo; vocábulos difíceis de serem compreendidos devido a pouca familiaridade entre a maioria dos usuários do serviço. Os operadores substituíram Juliete por Jogo, Fox por Faca e Bravo por Bola. Pode-se inferir que este procedimento constitui um mecanismo de regulação e resulta em uma forma de economia psíquica.

A norma da empresa determina que nesse processo seja utilizado como código associativo o alfabeto fonético internacional, baseado no idioma inglês e no alfabeto grego. Os operadores identificaram que as correspondências propostas pelo alfabeto fonético internacional muitas vezes difi- visando atingir os objetivos definidos, o operador utiliza os meios de que dispõe, levando em conta seu estado interno, seus conhecimentos, desenvolvendo assim um modo próprio e original de operar naquela situação. Entretanto, este modo operatório passará por constantes reajustes e novas orientações, em virtude da variabilidade das situações.

Nos exemplos apresentados observa-se que se os operadores não transgredissem e se limitassem às prescrições eles não atingiriam os objetivos do trabalho, além de seguramente contribuir para aumentar o número de chamadas, e nesse caso, ser confrontados a usuários ainda mais nervosos.

A sobrecarga de trabalho, o excesso de pressão, a necessidade de transgredir para poder atingir os objetivos do trabalho, dentre outros, aliados ao rigoroso controle adotado pela empresa, desencadeia nos operadores uma insatisfação, a qual pode explicar os conflitos entre o projeto espontâneo do trabalhador e a organização do trabalho. Na 
medida em que ela limita a sua realização enquanto sujeito, ao prescrever um modo operatório preciso, divide o trabalho e os trabalhadores, recortando de uma vez só o conteúdo das tarefas e as relações humanas no trabalho. Assim, "o trabalhador é, de certa maneira, despossuído de seu corpo físico e nervoso, domesticado e forçado a agir conforme a vontade de outro" (DEJOURS, ABDOUCHELI \& JAYET, 1994).

\section{Indicadores de saúde}

Resgatando estudos do início do século XX é possível constatar que, muitas das queixas hoje relatadas, repetem ou reformulam queixas do passado, dentre elas: as pressões temporal e de produção, a organização do trabalho rigorosa e inflexível, o controle ostensivo, as peculiaridades do atendimento ao público, o ambiente e os equipamentos de trabalho precários.

Uma parte das queixas relatadas neste estudo refere-se às características da própria atividade, outras, correspondem ao modelo de organização do trabalho adotado. Elas compõem um conjunto de características que faz com que esta atividade continue desgastante, fonte do que muitos chamam de "estresse", cansaço, fadiga e até sofrimento no trabalho. Todavia, foi possível constatar que determinadas questões do setor não evoluíram tanto quanto as tecnologias de informação, ponto de vista sustentado também por outros estudos na área (ECHTERNACHT, 1998; SANTOS, 1999).

O índice de rotatividade no serviço impressiona. Para constituir uma equipe de 50 funcionários, foram contratados e formados aproximadamente o dobro de operadores previstos, que, com o passar do tempo, foram saindo ou sendo substituídos. Quando indagados a respeito, os atendentes são claros quanto aos motivos que levaram os colegas a se retirarem: baixos salários, condições precárias de trabalho, falta de um plano de saúde e outros benefícios, serviço "estressante" (muita informação, muita pressão e responsabilidade, contato com o público), insatisfação com relação ao excesso de controle, falta de perspectiva de desenvolvimento, desvalorização dos funcionários por parte da empresa. Associadas a estas queixas estão ainda outras exigências da atividade, como manter uma mesma postura por muito tempo, realizar esforços repetitivos e manter constantemente a atenção na tela do computador e nos sinais auditivos.

Parafraseando Dejours, Abdoucheli e Jayet (1994), o homem é um sujeito que reage e se organiza mentalmente, afetivamente e fisicamente, em função de suas interpretações e significação de si no mundo. Trata-se de um sujeito que age sobre o processo de trabalho, contribuindo para a construção e evolução das relações sociais existentes. Podese derivar daí, a partir dos resultados encontrados neste estudo, que quando essa possibilidade é restrita, instaura-se o sofrimento. Inicialmente, este sujeito adota estratégias mediadoras socialmente aceitáveis, como o absenteísmo justificado.

A frequiência de atestados médicos e seus respectivos dias de licença constitui-se em um indicador da adoção de tais estratégias. $\mathrm{O}$ efetivo de trabalhadores na central de atendimento é de 50 funcionários, na listagem disponibilizada pela empresa constam 91, pois dela fazem parte todos os que trabalharam na central, inclusive aqueles que já tinham pedido demissão. A leitura desses dados mostra que dos 91 funcionários que passaram pela central nos seus três anos de funcionamento, apenas 1 nunca solicitou licença. Dos 90 restantes, 45 solicitaram licença uma vez, variando entre $1 \mathrm{e}$ 10 dias. Os outros 45 solicitaram licença mais de uma vez, variando entre 2 e 8 vezes, e de 1 a 19 dias.

Esses dados refletem, de certa forma, o que Dejours e Abdoucheli (1990) denominam sofrimentos patogênicos, responsáveis pela instauração de um circuito repetitivo de adoecimentos de toda ordem. O trabalhador torna-se incapaz de transformar criativamente o sofrimento patogênico, antes que ele se transforme em patológico e passe então a se manifestar pela linguagem da dor.

Quando as margens de negociação, as possibilidades de adaptação se esgotam, o trabalho se torna uma fonte permanente de conflito entre o sujeito e a organização do trabalho, emergindo sentimentos de insatisfação, tédio e ansiedade, até que o sofrimento comece a manifestar seu caráter patogênico. O sujeito, confrontado a essa situação e sem espaço para a descarga psíquica, opta por abandonar o emprego, o que certamente pode ser considerado como uma estratégia de autopreservação, acionando mecanismos de defesa para evitar sua descompensação. Possivelmente, esta seja uma das explicações para o alto índice de rotatividade encontrado nas centrais de atendimento.

Os atestados de saúde, associados à alta rotatividade, apontam o quanto a atividade, tal como está desenhada, permanece desgastante para os operadores. Quando circunscritos isoladamente, estes dados são reduzidos em seu grau de importância e desviados do seu curso, o de oportunizar juntamente com os demais indicadores, a compreensão do quadro das sinalizações do sofrimento humano no trabalho.

\section{À guisa de conclusão}

Este estudo foi desenvolvido em uma organização em que a natureza do trabalho - central de atendimento telefônico - exige dos operadores habilidade de comunicação; manutenção de um alto nível de concentração; paciência e cordialidade com o usuário; manejo adequado de situações críticas; elaboração de estratégias para evitar o fracasso e resistência à frustração resultante de um atendimento inconcluso. A resolução de problemas permeia de forma significativa a atividade desses operadores. No entanto, um rígido código de conduta limita a elaboração de respostas 
criativas pelos operadores. Diante da necessidade de levar a cabo suas atividades de forma efetiva, cria-se, paradoxalmente, uma contradição: o sucesso do trabalho assenta-se na transgressão. Possivelmente, uma das formas de dar sentido ao trabalho e resolver os problemas que são colocados é a transgressão do código de condutas.

A sobrecarga de trabalho, a pressão da demanda, a necessidade de transgredir para poder atingir os objetivos do trabalho, dentre outros, aliados ao rigoroso controle da organização gera um alto grau de insatisfação entre os operadores. O sofrimento que resultada do contexto do trabalho não pode ser evitado nem pela via da atividade - já que todas suas ações são rigorosamente prescritas a priori nem pela via da relação hierárquica, considerando o papel de controle atribuído aos supervisores.

No quadro geral da economia brasileira, em que o desemprego tornou-se uma ameaça efetiva, a demissão do traba- lho é colocada como uma última alternativa. Diante da percepção da impossibilidade de se desvincular do trabalho, os atendentes desenvolvem estratégias para justificar sua permanência no emprego e "resolver" os conflitos sociocognitivos e afetivos a que são submetidos. Após lançar mão das ações contidas nas prescrições, de transgredir o prescrito, os operadores, na busca de evitar o fracasso na realização da tarefa, reinterpretam a situação, justificando-a.

Finalmente, a possibilidade de abandono do emprego se apresenta, uma vez que as margens de negociação e as possibilidades de adaptação se esgotaram. Sem condições de resolver os constrangimentos impostos pelo trabalho e tentando resguardar sua saúde, o operador opta por demitirse, em uma clara estratégia de autopreservação. Esta é, certamente, uma das explicações para a constante renovação do quadro de operadores, o que implica em um elevado custo humano e financeiro.

\section{Artigo recebido em 07/07/2004 Aprovado para publicação em 22/11/2004}

\section{- Referências Bibliográficas}

ABRAHÃO, J.I. Reestruturação Produtiva e Variabilidade no Trabalho: Uma Abordagem da Ergonomia. Em: Psicologia: Teoria e Pesquisa, jan-abr 2000, vol. 16, n. 1, p. 49-54. Brasília, 2000.

ABRAHÃO, J.I. e SANTOS, V. O controle no trabalho: os seus efeitos no bemestar e na produtividade. Em: TAMAYO, A. (org.) Cultura e saúde nas organizações. Porto Alegre: Artmed, 2004.

CANÃS, J.J. \& WAERNS, Y. Ergonomía Cognitiva. Aspectos psicológicos de la interaccioón de las personas com la tecnología de la información. Madrid: Editorial Médica Panamericana, S.A., 2001.

DEJOURS, C. Organisation du Travail - clivage - alienation. Em: DEJOURS, C., VEIL,C., WISNER, A. Psychopatologie du travail. Paris: EME, p.123-30, 1985.

DEJOURS, C. A loucura do trabalho. São Paulo: Editora FTA/Oboré, 1987.

DEJOURS, C. L'évaluation du travail à l'épreuve du réel. Critique des fondements de l'évaluation. Paris: INRA, 2003.

DEJOURS,C. e ABDOUCHELI, E. Itinéraire théorique en psychopatologie du travail. Em: Revue Prevenir. Travail et santé mentale, n. 20 , $1^{\text {er }}$ semestre, p.127-147. Paris, 1990.
DEJOURS, C.; ABDOUCHELI, E. \& JAYET, C. Psicodinâmica do Trabalho Contribuições da Escola Dejouriana à análise da relação Prazer, Sofrimento e Trabalho. São Paulo: Editora Atlas S.A., 1994.

DEJOURS, C. \& MOLINIER, P. Le travail comme énigme. Em: Sociologie $d u$ Travail. XXXVI, Hors série. Paris, 3544, 1994

ECHTERNACHT, E.H.O. As Lesões por Esforços Repetitivos no Contexto de Reestruturação Produtiva Brasileira. Tese de doutorado. GENTE/COPPE/UFRJ. Rio de Janeiro, 1998.

GUÉRIN, F.; LAVILLE, A.; DANIELLOU, F. DURRAFOURG, J. \& KERGUELLEN, A. Comprendre le travail pour le transformer. La pratique de l'Ergonomie. Paris: Ed. ANACT, 1991.

GUBERT, K.B. Os determinantes da atividade em uma central de atendimento: o caso do disque-saúde. Dissertação de mestrado. Universidade de Brasília. Brasília, 2001.

KARAM, H. O sujeito entre a alcoolização e a cidadania: perspectiva clínica do trabalho. Em: Revista de Psiquiatria do Rio Grande do Sul, set./dez. 2003, v. 25, n. 3, p. 468-474. Rio Grande do Sul, 2003.

KUPFER, M. C. Freud e a Educação. São Paulo: Scipione, 3. ed., 2000.
LE GUILLANT, L. Quelle psyquiatrie pour notre temps? Toulouse: Éditions Érès, 1956.

MARMARAS, N. \& KONTOGIANS, T. Cognitive Task. Em: G. SALNEND Handbook of Industrial Engineering. New York: John Wiley \& Sons, 2001.

MARMARAS, N. \& PAVARD, B Problem-Driven Approach to the Desing of Information Technology Systems Supporting Complex Cognitive Tasks. Em: Cognition, Technology \& Work,1, 222-236, 1999.

RAPPAPORT, C. R.; FIORI, W. R.; DAVIS, C. Psicologia do Desenvolvimento. São Paulo: EPU, 1981.

RASMUSSEM, J. Human factors in a dynamic information society: where are we heading? Ergonomics, 43 (7), 869-879, 2000.

SANTOS, V. As Centrais de Atendimento. www.ergonomia.com.br, 1999.

SANTOS, V. A ergonomia e a intensificacão do trabalho nas centrais de atendimento: a gestão temporal de múltiplas tarefas $e$ de tarefas interferentes. Tese de doutorado, COPPE - Universidade do Rio de Janeiro. Rio de Janeiro, 2002.

TAJFEL, H (1981/1982). Grupos humanos e categorias sociais: estudos em psicologia social. (Tradução de Lígia Amância). Lisboa: Livros Horizontes.
TEIGER, C. Le travail, cet obscur objet de l'érgonomie. Em: Actes du Colloque Interdisciplinaire "Traval: Recherche et prospective" - Thème Transversal $\mathrm{N}$. 1 - Concept de Travail. CNRS, PIRTTEM, ENS de Lyon, 1992.

TERSSAC, G. Le travail organisé: Fautil repenser le travail?. Em: Actes du XXX Congrès de la Société d'Érgonomie de Langue Française, Biarritz, França, 1995.

TORRES, C.C. A atividade nas centrais de atendimento: outra realidade, as mesmas queixas. Dissertação de Mestrado. Universidade de Brasília. Brasília, 2001.

VILELA, L.V. de O. e ASSUNÇÃO, A.A Os mecanismos de controle da atividade no setor de teleatendimento e as queixas de cansaço e esgotamento dos trabalhadores. Em: Cadernos de Saúde Pública, , 20(4), jul-ago, p.10691078, , Rio de Janeiro 2004.

WEILL-FASSINA, A.; RABARDEL, P.; DUBOIS, D. Représentations pour l'actions. 1. Ed. Toulouse: Octares Editions, 1993.

WISNER, A. Por dentro do trabalho. Ergonomia: método e técnica. São Paulo: Editora FTA/Oboré, 1987.

WISNER, A. Ergonomie et psychopatologie du travail. Em: Revue Prevenir. Travail et santé mentale, n. 20, $1^{\mathrm{er}}$ semestre, p. 65-73. Paris, 1990. 